\title{
Isolated Laryngeal Lymphangioma: A Case Report and Literature Review
}

\author{
${ }^{1} \mathrm{~N}$ Raja Sekharam, ${ }^{2}$ Manoj Sharma, ${ }^{3} \mathrm{~N}$ Vishnu S Reddy, ${ }^{4}$ Murali Chintham, ${ }^{5}$ Priyanka Sharma, ${ }^{6}$ Rajesh Gudipudi
}

\begin{abstract}
Introduction: Lymphangiomas of larynx are extremely rare congenital lesions of lymphatic system. Most commonly seen in head and neck region, about $90 \%$ of them are detected by the second year of life. Adult laryngeal lymphangioma is very rare in occurrence with only a few cases reported in the literature.
\end{abstract}

Case report: We report a rare case of isolated laryngeal lymphangioma, which was well treated by tracheostomy and thorough surgical excision using rigid endoscope with diode laser ablation without injuring the surrounding vital laryngeal structures.

Conclusion: We discuss the presentation, diagnosis, and treatment of laryngeal lymphangioma with possible options for surgical management along with a review of pertinent literature.

Keywords: Laryngeal lesion, Laryngeal lymphangioma, Tracheostomy.

How to cite this article: Sekharam NR, Sharma M, Reddy NVS, Chintham M, Sharma P, Gudipudi R. Isolated Laryngeal Lymphangioma: A Case Report and Literature Review. Int J Otorhinolaryngol Clin 2018;10(2):66-69.

Source of support: Nil

Conflict of interest: None

\section{INTRODUCTION}

Lymphangiomas are rare congenital cystic malformations consisting of abnormal development of the lymphatic system in localized regions. Lymphangiomas are classified as capillary hemangiomas, cavernous hemangiomas, and cystic hygromas according to the size of the lymphatic cavities incorporated. ${ }^{1}$

Lymphangioma in an adult is seen very infrequently. Symptoms of laryngeal lymphangioma are essentially the same as those caused by other type of benign lesions.

Our literature search for laryngeal lymphangioma in adults revealed only few cases in the last seven decades. We are reporting the case of a 50-year-old female who

\footnotetext{
${ }^{1,4}$ Consultant, ${ }^{2}$ Resident, ${ }^{3}$ Head, ${ }^{5,6}$ Senior Resident

1-4,6 Department of ENT, Care Hospital, Hyderabad, Telangana India

${ }^{5}$ Department of ENT, Mayo Institute of Medical Sciences Lucknow, Uttar Pradesh, India

Corresponding Author: Manoj Sharma, Resident, Department of ENT, Care Hospital, Hyderabad, Telangana, India, e-mail: dr.sharmamanoj@yahoo.com
}

presented with discomfort in throat and stridor. The tumor excision was done and histopathology revealed the diagnosis of isolated laryngeal lymphangioma. There is no evidence of recurrence after 2 years.

\section{CASE REPORT}

A 50-year-old female patient presented in the outpatient department with progressively increasing stridor since 1 week. She was suffering from dry cough and throat discomfort since 6 months. Examination of oral cavity and oropharynx was insignificant.

Further flexible laryngoscopy revealed a smooth, spherical, circumscribed swelling occupying the laryngeal inlet with anteriorly pushed epiglottis, other laryngeal structures including vocal cords were not visualized. Later, emergency tracheostomy was performed.

Contrast-enhanced magnetic resonance imaging (MRI) has shown a well-defined pedunculated mass in the hypopharynx $2.2 \times 2.3 \times 2.2 \mathrm{~cm}$ in dimensions (Fig. 1), completely obliterating the airway with anterior displacement of epiglottis and thickening of bilateral aryepiglottic folds.

The differential diagnosis of benign tumor of larynx was made. Then the microlaryngoscopic excision of tumor was planned. During surgery, the margins of tumor could not be delineated with laryngoscope, as it was completely occupying the supraglottic region. The attachment of tumor to right arytenoid was released with great difficulty by using microlaryngeal scissors.

Due to inadequate exposure of lesion, a transoral endoscopic excision of the tumor was done using $70^{\circ}$, $4 \mathrm{~mm}$ rigid endoscope, and laparotomy scissors. The residual tumor was ablated using diode laser and absolute hemostasis was achieved.

\section{Histopathology}

The sections of the dissected specimen showed polypoidal lesion composed of dilated thin walled spaces lined by a single layer of flattened cells. The stroma in between has dense lymphoid aggregates forming lymphoid follicles. The histopathological diagnosis was consistent with lymphangioma.

Follow-up was done by flexible laryngoscopy every 3 months. There is no evidence of tumor recurrence after regular follow-up for 2 years (Fig. 2). 


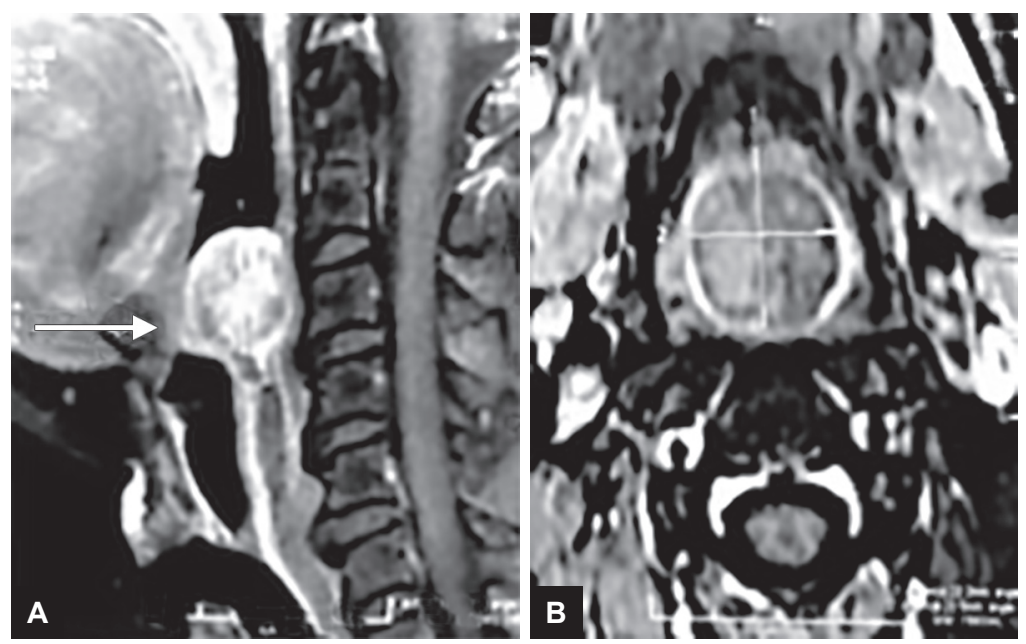

Figs 1A and B: (A) Preoperative MRI sagittal section showing a well-defined mass posterior to epiglottis. (B) MRI axial section showing mass occupying the airway
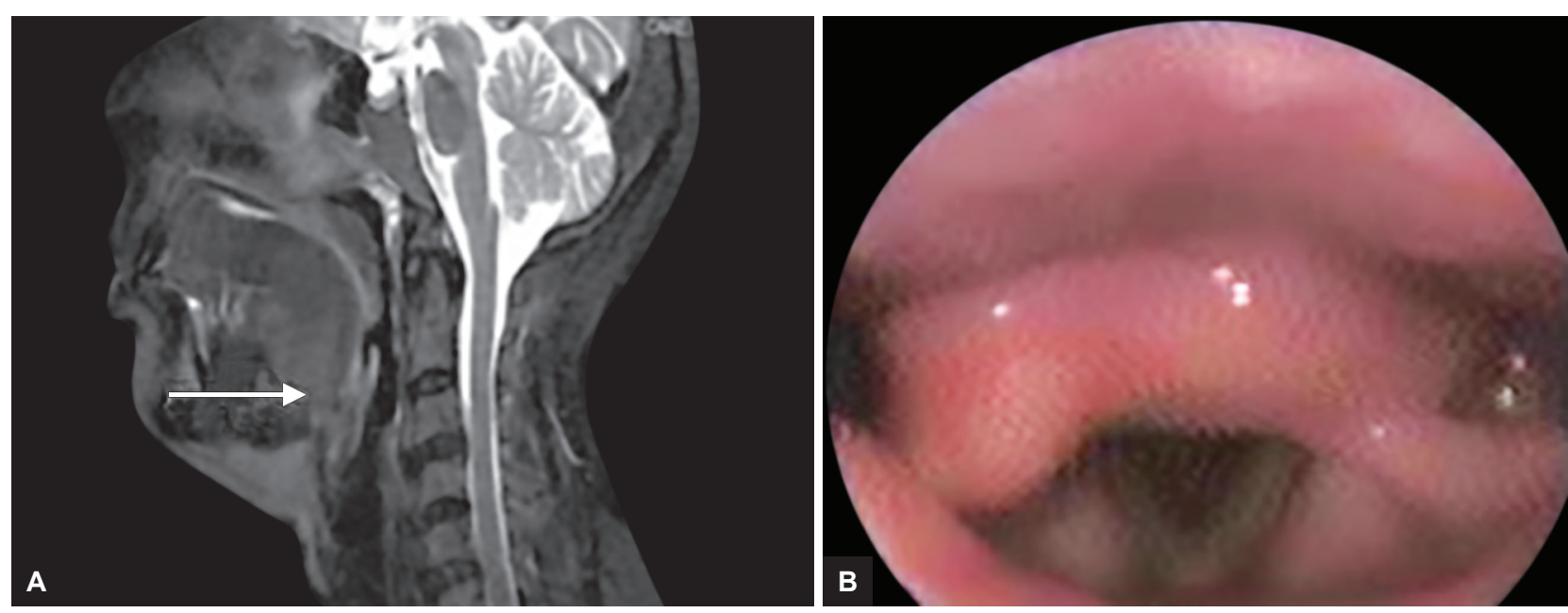

Figs 2A and B: (A) Postoperative MRI scan (sagittal section). (B) Postoperative endoscopic view of larynx

\section{DISCUSSION}

According to a theory proposed by McClure and Silvester, ${ }^{2}$ when primordial lymphatic sacs fail to connect to the venous system with which they normally communicate, it leads to development of lymphangioma.

It mostly arises in head and neck region with often neck being quoted as the most common site. Among all lymphatic malformations, 50 to $60 \%$ are present at birth and approximately 80 to $90 \%$ become evident by the age of 2 years; however, some may manifest much later in life.

Lymphangiomas can occur in larynx but are extremely rare. These solely confined laryngeal lesions are rarely found in adult population, only few adult cases (abstract available) have been reported in the literature in past 70 years (Table 1 ).

Friction caused by food bolus and numerous lymphatic vessels makes the laryngeal inlet structures including lingual surface of epiglottis, aryepiglottic folds, and arytenoid region more vulnerable for laryngeal lymphangioma. Invasion of this tumor to surrounding structures is not seen as lesions are covered by distinct capsule.

The symptoms are nonspecific and vary with the site and size of the mass, the major symptoms include airway obstruction and voice changes, indicating large obstructive lesion or vocal cord lesions respectively. ${ }^{3}$ In case of any infection within the mass, more serious symptoms should be expected due to rapid growth of the mass with associated edema, and sometimes may lead to complications, such as acute airway obstruction and hemorrhage.

The MRI can demarcate the mass from the surrounding tissues and provides information about the extent of the lesion. Contrast-enhanced computed tomography scan and ultrasound of the neck can also be helpful in determining the exact anatomical location of these lesions.

The confirmative diagnosis can only be made after biopsy and histopathological examination. 
Table 1: Adult patients presenting with laryngeal lymphangioma (age more than 18 years)

\begin{tabular}{|c|c|c|c|c|c|c|}
\hline $\begin{array}{l}\text { Year } \\
\text { reported }\end{array}$ & Sex & $\begin{array}{l}\text { Age at } \\
\text { presentation }\end{array}$ & $\begin{array}{l}\text { Presenting } \\
\text { symptom(s) }\end{array}$ & Maximal extent of disease & Therapy instituted & Outcome \\
\hline $1948^{9}$ & M & 28 years & Dyspnea & Posterior wall of larynx & $\begin{array}{l}\text { Direct laryngoscopy and } \\
\text { excision }\end{array}$ & No recurrence \\
\hline $1985^{10}$ & $\mathrm{~F}$ & 36 years & Hoarseness of voice & Right false vocal cord & $\begin{array}{l}\text { Tracheostomy, } \\
\text { laryngofissure }\end{array}$ & No recurrence \\
\hline $1991^{11}$ & $\mathrm{~F}$ & 69 years & Globus pharyngeus & Postcricoid surgery region & Pharyngoscopy and excision & Not described \\
\hline $2003^{12}$ & $\mathrm{~F}$ & 47 years & Hoarseness of voice & Right laryngeal ventricle & $\begin{array}{l}\text { Microlaryngeal (cold } \\
\text { instruments) }\end{array}$ & No recurrence \\
\hline $2004^{3}$ & $\mathrm{~F}$ & 37 years & Acute epiglottitis & Epiglottis (lingual surface) & $\begin{array}{l}\text { Suspension } \\
\text { microlaryngoscopy (cold } \\
\text { instruments) }\end{array}$ & No recurrence \\
\hline $2006^{7}$ & $\mathrm{~F}$ & 26 years & Dyspnea on exertion & $\begin{array}{l}\text { Right supraglottis, medial } \\
\text { and lateral to thyroid lamina }\end{array}$ & $\begin{array}{l}\text { Sclerotherapy, tracheostomy, } \\
\text { and transcervical excision }\end{array}$ & No recurrence \\
\hline
\end{tabular}

To provide adequate airway, the tracheostomy is almost always required in large lesions.

As lymphangioma rarely regresses spontaneously, many approaches have been described for the treatment. The treatment options include, surgical excision, laserassisted debulking with ablation, sclerotherapy, and corticosteroids. ${ }^{4}$

Sclerotherapy is safe, with a high cure rate, especially with agents, such as OK-432; ${ }^{5}$ other sclerosants include bleomycin, ${ }^{6}$ ethanol, and acetic acid. Vaishali et al ${ }^{7}$ reported a case of a 26-year-old female with lymphangioma larynx who presented with right-sided neck swelling since birth who had undergone surgery at the age of 10 years. The swelling had reappeared at the age of 16 years, and was asymptomatic until the age of 23 years. Patient underwent tracheostomy and thereafter 10 sclerosant injection sessions were performed. Six months after sclerotherapy, she underwent transcervical dissection and excision of lesion. During dissection, extensive fibrosis was encountered probably due to the previous sclerotherapy.

Neodymium-doped yttrium aluminum garnet laserassisted surgery has become a widely preferred method because it is associated with less bleeding and edema as compared with other conventional methods.

The surgical excision should be so extensive and conservative to provide complete removal with minimal risk of local recurrence and functional preservation of adjacent vital structures.

The radiation therapy is not effective in the treatment of these lesions and is associated with secondary malignancies. ${ }^{8}$

To date, no randomized controlled trials have demonstrated the superiority of one modality of treatment over another. Individualization of treatment is required in most cases depending on type, extent, and location of lesion. Even with complete excision of tumor, the recurrence rate of these lesions is high.
We report this case because of the unusual site of involvement and the age of presentation. As laryngeal lymphangioma is a very rare entity in adults, so it should be kept in differential diagnosis of any benign lesions of larynx.

\section{SUMMARY}

- Laryngeal lymphangioma is rare benign tumor in the adult and we should keep in mind lymphangioma as a differential diagnosis of benign laryngeal lesions.

- Large laryngeal lesions can lead to airway compromise and difficulty in intubation, so tracheostomy should be done before proceeding to the excision or laser ablation of tumor.

- The rigid endoscopes can be used in cases of difficulty in delineating the tumor margins as the laryngoscope gives a limited view of lesion as seen in this case.

- Finally, whatever the technique is used, either surgical excision or laser ablation, disease clearance without injuring the surrounding vital structures is very important.

\section{REFERENCES}

1. Bloom DC, Perkins JA, Manning SC. Management of lymphatic malformations. Curr Opin Otolaryngol Head Neck Surg 2004 Dec;12(6):500-504.

2. McClure CFW, Silvester CF. A comparative study of the lymphatic-venous communications in adult mammals. Anat Rec 1909 Oct;3(10):534-553.

3. Seven H, Topuz E, Turgut S. Isolated laryngeal lymphangioma showing the symptoms of acute epiglottitis. Eur Arch Otorhinolaryngol 2004 Nov;261(10):548-550.

4. Gupta N, Goyal A, Singh PP, Sharma S. Isolated laryngeal lymphangioma: A rarity. Indian J Otolaryngol Head Neck Surg 2011 Jul;63(Suppl 1):90-92.

5. Giguere CM, Bauman NM, Sato Y, Burke DK, Greinwald JH, Pransky S, Kelley P, Georgeson K, Smith RJ. Treatment of lymphangiomas with OK-432 (Picibanil) sclerotherapy: A prospective multi-institutional trial. Arch Otolaryngol Head Neck Surg 2002 Oct;128(10):1137-1144. 
6. Muir T, Kirsten M, Fourie P, Dippennar N, Ionescu GO. Intralesional bleomycin injection (IBI) treatment for haemangiomas and congenital vascular malformations. Pediatr Surg Int 2004 Jan;19(12):766-773.

7. Vaishali B, Nambiar A, Indudharan R. Lymphangioma of the larynx. J Laryngol Otol 2007 Apr;121(4):e2.

8. Haksever M, Akduman D, Aslan S, Yazla S, Haksever H. Nasopharyngeal lymphangioma in an adult: A rarity. Laryngoscope 2013 Dec;123(12):2972-2975.
9. Cordray DP, Gervais RF. Lymphangioma of the larynx. AMA Arch Otolaryngol 1951 Jan;53(1):83-86.

10. NaitoK, IwataS, Nishimura T, Yagisawa M,SakuraiK. Laryngeal lymphangioma. Auris Nasus Laryx 1985;12(2):111-116.

11. Smith NM, Stafford FW. Post cricoid lymphangioma. J Laryngol Otol 1991;105:220-221.

12. Cinar U, Yiğit $\mathrm{O}$, Başak T, Dadaş B. Cavernous lymphangioma in the laryngeal ventricle in an adult patient. Kulak Burun Bogaz Ihtis Derg 2003 Oct;11(4):117-120. 